GABA-GABA: Jurnal Pengabdian Masyarakat dalam Bidang Pendidikan Bahasa dan Seni

Vol. 1, No. 1, April 2021, Hal. 30 - 35

e-ISSN .....

\title{
PENGEMBANGAN MATERI PEMBELAJARAN BERDASARKAN KONSTRUKTIVISME SOSIAL MELALUI PENDEKATAN SCAFFOLDING
}

\author{
Jolanda Tomasouw ${ }^{1}$, Juliaans Eliezer Rulland Marantika ${ }^{2}$, Cornelia S. Maitimu, Vika Lestari \\ ${ }^{1}$ Pendidikan Bahasa Jerman, FKIP Universitas Pattimura; marland_mt@yahoo.co.id \\ ${ }^{2}$ Pendidikan Bahasa Jerman, FKIP Universitas Pattimura; julians.marantika@yahoo.com
}

\begin{abstract}
Abstrak: Kualitas pendidikan di Indonesia, terutama di Maluku, sedang disorot oleh banyak ahli. Hal utama yang menjadi fokus adalah menurunnya kualitas pembelajaran di sekolah, yang berdampak pada kualitas dan daya saing siswa di tingkat lokal dan nasional. Berdasarkan apa yang dijelaskan di atas, sistem pembelajaran dan bahan ajar di tingkat sekolah menengah di Ambon perlu ditinjau kembali. Melalui pengembangan bahan ajar bahasa Jerman berdasarkan pendekatan scaffolding, diharapkan prestasi belajar bahasa Jerman siswa SMA akan meningkat. Oleh karena itu, tujuan dari penelitian ini adalah sebagai berikut: (1) mampu mengembangkan materi Bahasa Jerman untuk Sekolah Menengah Atas di Ambon (2) mencoba kinerja pengajaran menggunakan bahan yang dikembangkan dalam rangka penyempurnaan dan standardisasi Pembelajaran Bahasa Jerman. Materi berdasarkan pendekatan scaffolding. Metode yang digunakan dalam penelitian ini adalah metode pengembangan berdasarkan model ADDIE. Hasil penelitian ini dapat direplikasi oleh semua sekolah menengah atas di Maluku. Hasil yang ingin dicapai serta tindak lanjut dari penelitian ini diharapkan menghasilkan Bahan Ajar Bahasa Jerman Berbasis Scaffolding untuk Sekolah Menengah Atas.
\end{abstract}

Kata Kunci: Bahan Ajar, Konstruktivisme, Pendekatan Scaffolding

Abstract: The quality of education in Indonesia, especially in Maluku, is being highlighted by many experts. The main things that been focused are declining quality of learning in schools, which have an impact on the quality and competitiveness of the students at locally and nationally level. Based on what is described above, the learning system and teaching materials at high school level in Ambon need to be reviewed. Through the development of German language teaching materials based on scaffolding approach, it is expected that the German language learning achievement of high school students will increase. Therefore, the objectives of the research are as follows: (1) Able to Develop German Language material for High School in Ambon (2) to try out the performance of the teaching using the developed material in order to refinement and standardization of the German Language Learning Material based on Scaffolding approach. The method used in this research is the development method based on ADDIE model. The output of this research can be replicated by all high schools in Maluku. The outcomes to be achieved as well as the follow-up of this research are expected to result the Scaffolding-Based German Language Learning Materials for High School.

Keywords: Learning Material, Constructivism, Scaffolding Approach.

\section{PENDAHULUAN}

Pembelajaran saat ini masih terfokus pada pola pembelajaran konvensional. Hal ini mengakibatkan siswa kurang kreatif. Hal ini menyebabkan penurunan kualitas pengajaran yang berdampak pada hasil belajar siswa. Materi dan metode merupakan indikator pencapaian hasil belajar siswa. Oleh karena itu pembelajaran harus dirancang sesuai tingkat kemampuan peserta didik sehingga pembelajaran itu menyenangkan dan mampu meningkatkan motivasi siswa dengan memperhatikan metode pembelajaran yang digunakan. Scaffolding adalah salah satu metode yang dapat membantu siswa untuk lebih aktif dalam pembelajaran. Menurut (Könings ,Zundert, Merrienboer: 2018: 84), Scaffolding memiliki manfaat yang sangat bagi pembelajar karena scaffolding mampu mengurang beban kognitif pembelajar selama proes pembelajaran berlangsung serta dapat meningkatkan akurasi pada tugas-tugas khusus domain.

[Type here] 
Metode pembelajaran Scaffolding dapat diartikan sebagai suatu teknik pemberian dukungan belajar secara terstruktur, yang dilakukan pada tahap awal untuk mendorong siswa agar dapat belajar secara mandiri. Pemberian dukungan belajar ini tidak dilakukan secara terus menerus, tetapi seiring dengan terjadinya peningkatan kemampuan siswa, secara berangsur-angsur guru harus mengurangi dan melepaskan siswa untuk belajar secara mandiri. Jika siswa belum mampu mencapai kemandirian dalam belajarnya, guru kembali ke sistem dukungan untuk membantu siswa memperoleh kemajuan sampai mereka benar-benar mampu mencapai kemandirian. Dengan demikian, esensi dan prinsip kerjanya tampaknya tidak jauh berbeda dengan scaffolding dalam konteks mendirikan sebuah bangunan. Pembelajaran Scaffolding sebagai sebuah teknik bantuan belajar (assisted-learning) dapat dilakukan pada saat siswa merencanakan, melaksanakan dan merefleksi tugas-tugas belajarnya.

Scaffolding didasarkan pada teori Vygotsky tentang konsep pembelajaran dengan bantuan (Assisted Learning). Menurut teori ini, fungsi-fungsi mental yang lebih tinggi termasuk didalamnya kema mpuan untuk mengarahkan memori dan antensi untuk tujuan tertentu serta kemampuan untuk berpikir dalam simbol-simbol yang merupakan perilaku yang memerlukan bantuan, dengan mendapatkan bantuan secara eksternal (dari luar diri siswa) oleh budaya, perilaku itu masuk dan melekat dalam benak siswa sebagai alat psikologis (Nur dan Wikandari, 2000:13).

Hal tersebut diatas ditambahkan oleh (Gibbons, Pauline., 2015:16), bahwa Scaffolding merupakan salah satu jenis bantuan khusus yang membantu pembelajar untuk menemukan hal-hal baru dalam keterampilan, konsep, atau tingkat pemahaman. Bantuan yang diberikan guru tersebut bersifat sementara untuk mengetahui bagaimana melakukan sesuatu dan selanjutnya pembelajar nantinya akan dapat menyelesaikan tugas yang sama saja

Pembelajaran dengan bantuan, guru adalah agen budaya yang memandu pengajaran sehingga siswa akan menguasai secara tuntas keterampilan-keterampilan yang memungkinkan fungsi kognitif yang lebih tinggi (Nur dan Wikandari, 2000:14).. Pendekatan kognitif mengutamakan proses internalisasi ingatan, retensi, pengelolaan informasi, emosi, skemata dan faktor lainnya dalam struktur kognitif pembelajar. Itu berarti segala upaya yang dilakukan dalam sebuah proses pembelajaran bahasa Jerman harus mengarah pada peningkatan kompetensi untuk memahami informasi atau materi pembelajaran secara kontekstual dengan melibatkan berbagai unsur.

Secara operasional, pembelajaran Scaffolding dapat ditempuh melalui tahapan berikut: (1).Melaksanakan assesmen kemampuan awal dan taraf perkembangan setiap siswa untuk menentukan Zone of Proximal Develpment (ZPD), yakni wilayah perkembangan siswa yang masih berpotensi dan berpeluang untuk ditingkatkan dan dioptimalkan melalui bantuan guru, teman, atau lingkungan pembelajaran tertentu, termasuk di dalamnya pemanfaatan teknologi. (2). Menjabarkan tugas-tugas dan aktivitas belajar secara rinci sehingga dapat membantu siswa melihat zona yang perlu di-scaffold. (3). Menyajikan struktur/tugas belajar secara jelas dan bertahap sesuai taraf perkembangan siswa, yang dapat dilakukan melalui: penjelasan, dorongan (motivasi) dan pemberian contoh (modeling). Sedangkan menurut Beese et.al (2014:43), Scafffolding terbagi atas dua bagian yakni Makro-dan Mikro Scaffolding yang dapat digambarkan pada Gambar 1.

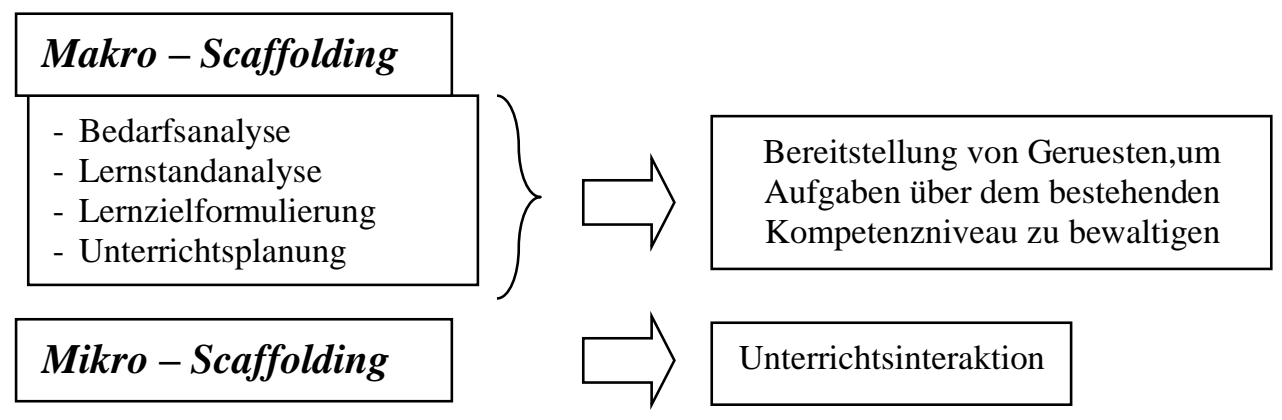

Gambar 1. Mikro-Makro Scaffolding Kompetenz 
Gambar di atas menjelaskan bahwa, melalui Makro-scaffolding kompetensi kebahasaan pembelajar akan lebih terfokus terutama lewat rencana pembelajaran, disamping itu pengajar merupakan motor yang dapat mengukur ketercapaian tujuan pembelajaran maupun keberhasilan siswa atau pembelajar. Sedangkan Mikro-Scaffolding lebih menitik beratkan pada interaksi dalam pembelajaran kebahasaan baik dalam dalam berpasangan maupun dalan kelompok.

Ketika dalam interaksi sosial dikelas, terjadi saling tukar pendapat antar siswa dalam memecahkan suatu masalah, maka disitulah akan terjadi apa yang disebut dengan Scaffolding. Menurut (Tomasouw, 2015:9), interaksi sosial akan terbangun melalui pendampingan teman sebaya dalam proses belajar mengajar. Hal ini merupakan salah satu indikator penting yang dapat menunjang hasil belajar. Berbicara tentang pendampingan atau pembimbingan bagi tutor sebaya memerlukan pendekatan tersendiri. Keberadaan siswa saat ini sangat tidak stabil dalam arti mereka masih mencari jati diri mereka dan hal itu sangat berpengaruh baik dalam proses belajar mengajar maupun hasil belajar. Dengan demikian dibutuhkan suatu pendekatan yang dikenal dengan Scaffolding.

Berdasarkan uraian diatas dapat dikatakan bahwa pendekatan Scaffolding yang dimaksudkan dalam penelitian ini adalah pendekatan yang mampu mengembangkan kognitif siswa melalui bahan ajar dengan menitikberatkan pada tujuan pembelajaran, isi materi, tingkat kemampuan, metode, media dan faktor kebahasaan

Bahan ajar adalah seperangkat sarana atau alat pembelajaran yang berisikan materi pembelajaran, metode, batasan-batasan, dan cara mengevaluasi yang didesain secara sistematis dan menarik dalam rangka mencapai tujuan yang diharapkan, yaitu mencapai kompetensi atau subkompetensi dengan segala kompleksitasnya (Widodo dan Jasmadi dalam Lestari, 2013:1). Pengertian ini menjelaskan bahwa suatu bahan ajar haruslah dirancang dan ditulis dengan kaidah intruksional karena akan digunakan oleh guru untuk membantu dan menunjang proses pembelajaran. Bahan atau materi pembelajaran pada dasarnya adalah "isi" dari kurikulum, yakni berupa mata pelajaran atau bidang studi dengan topik/subtopik dan rinciannya (Ruhimat, 2011:152).

Pada prinsipnya bahan ajar memiliki beberapa karakteristik, yaitu self instructional, self contained, stand alone, adaptive, dan user friendly (Widodo dan Jasmadi dalam Lestari, 2013 : 2). Pertama, self instructional yaitu bahan ajar dapat membuat siswa mampu membelajarkan diri sendiri dengan bahan ajar yang dikembangkan. Untuk memenuhi karakter self instructional, maka di dalam bahan ajar harus terdapat tujuan yang dirumuskan dengan jelas, baik tujuan akhir maupun tujuan antara. Selain itu, dengan bahan ajar akan memudahkan siswa belajar secara tuntas dengan memberikan materi pembelajaran yang dikemas ke dalam unit-unit atau kegiatan yang lebih spesifik. Kedua, self contained yaitu seluruh materi pelajaran dari satu unit kompetensi atau subkompetensi yang dipelajari terdapat di dalam satu bahan ajar secara utuh. Jadi sebuah bahan ajar haruslah memuat seluruh bagian-bagiannya dalam satu buku secara utuh untuk memudahkan pembaca mempelajari bahan ajar tersebut. Ketiga, stand alone (berdiri sendiri) yaitu bahan ajar yang dikembangkan tidak tergantung pada bahan ajar lain atau tidak harus digunakan bersama-sama dengan bahan ajar lain. Artinya sebuah bahan ajar dapat digunakan sendiri tanpa bergantung dengan bahan ajar lain. Keempat, adaptive yaitu bahan ajar hendaknya memiliki daya adaptif yang tinggi terhadap perkembangan ilmu dan teknologi. Bahan ajar harus memuat materi-materi yang sekiranya dapat menambah pengetahuan pembaca terkait perkembangan zaman atau lebih khususnya perkembangan ilmu dan teknologi. Kelima, user friendly yaitu setiap intruksi dan paparan informasi yang tampil bersifat membantu dan bersahabat dengan pemakainya, termasuk kemudahan pemakai dalam merespon dan mengakses sesuai dengan keinginan. Jadi bahan ajar selayaknya hadir untuk memudahkan pembaca untuk mendapat informasi dengan sejelas-jelasnya.

Secara garis besar, fungsi bahan ajar bagi guru adalah untuk mengarahkan semua aktivitasnya dalam proses pembelajaran sekaligus merupakan subtansi kompetensi yang seharusnya diajarkan kepada siswa. Fungsi bahan ajar bagi siswa untuk menjadi pedoman dalam proses pembelajaran dan merupakan subtansi kompetensi yang seharusnya dipelajari. Bahan ajar juga berfungsi sebagai alat evaluasi pencapaiana hasil pembelajaran. Bahan ajar yang baik sekurang-kurangnya mencakup petunjuk belajar, kompetensi yang akan dicapai, isi pelajaran, informasi pendukung, latihan-latihan, petunjuk kerja, 
evaluasi dan respon terhadap hasil evaluasi (Prastowo dalam Lestari, 2011: 2004). Karakteristik siswa yang berbeda berbagai latar belakangnya akan sangat terbantu dengan adanya kehadiran bahan ajar, karena dapat dipelajari sesuai dengan kemampuan yang dimilki sekaligus sebagai alat evaluasi penguasaan hasil belajar karena setiap hasil belajar dalam bahan ajar akan selalu dilengkapi dengan sebuah evaluasi guna mengukur penguasaan kompetensi. Berdasarkan strategi pembelajaran yang digunakan, fungsi bahan ajar dapat dibedakan menjadi tiga macam, yaitu fungsi dalam pembelajaran klasikal, pembelajaran individual, dan pembelajaran kelompok (Prastowo dalam Lestari, 2011: 25- 26).

Dengan demikian maka bahan ajar bahasa Jerman yang dirancang hendaknya senantiasa merangsang siswa untuk berperan aktif dalam kegiatan pembelajaran sehingga mampu meningkatkan hasil belajar bahasa Jerman siswa SMA, dengan memperhatikan kriteria-kriteria dalam penyusunan bahan ajara bahasa Jerman pada Gambar 2.

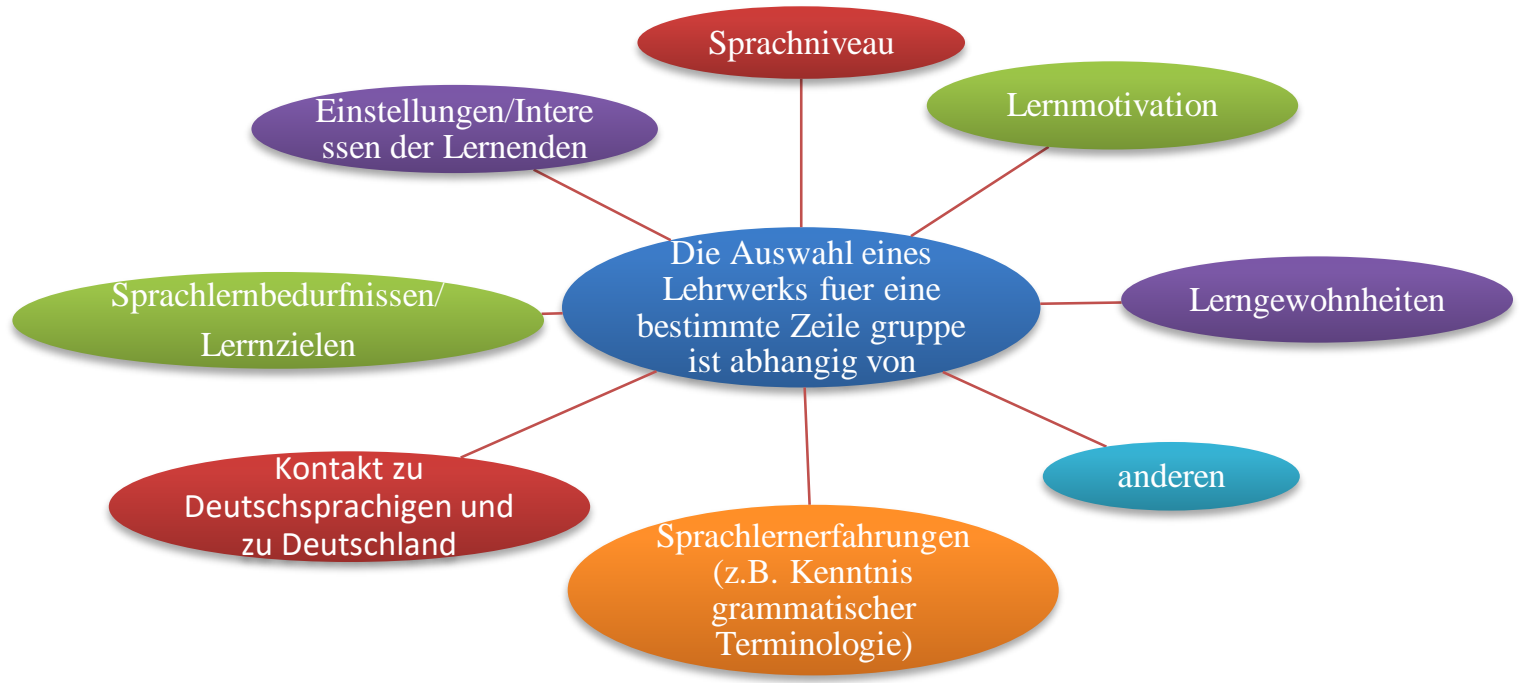

Gambar 2. Zielgruppen von Lehrwerken.

Gambar di atas menjelaskan bahawa pemilihan suatu bahan ajar untuk kelompok tertentu tergantung pada beberapa aspek antara lain : (a) kemampuan berbahasa; (b) motivasi belajar; (c) Lingkungan belajar; (d) pengalaman belajar bahasa; (e).kemampuan berbahasa asing lain disamping bahasa Jerman; (f) minat pembelajar; (g) kontakt kebahasaan; (h) Tujuan pembelajaran. Disamping itu Rosler dan Wurfel (2014:56) mengemukakan juga tentang Kriteria Penilaian Bahan Ajar Bahasa Jerman dengan memperhatikan yaitu Komponenten des Lehrwerks, Lernziele, Aufbau des Lehrwerks, Progression, Themen,/Inhalte, Kontrastivität, Medien und Gestaltung.

Bahan ajar yang dirancang dapat menggunakan strategi scaffolding seperti pemodelan, penataan kognitif, memberikan informasi, mendorong pemantauan diri, dan menegaskan sebagai sarana untuk membantu kinerja siswa di kelas (Banyak, 2002; Tharp \& Gallimore, 1988) dalam (Many* Donna L. Taylor $\uparrow$ Yan Wangł Gertrude T. Sachs** Heidi Schreiber, 2007:19). Disamping itu juga scaffoldin dapat dibentuk secara luas untuk instruksi yang sudah direncanakan sebelumnya oleh guru dan juga oleh instruksi responsif yang ditentukan oleh kebutuhan mereka yang berpartisipasi (Joyce E. Many* Donna L. Taylor† Yan Wang $\ddagger$ Gertrude T. Sachs** Heidi Schreiber, 2007:19)

\section{METODE}

Metode yang digunakan dalam penelitian ini adalah metode penelitian pengembangan. Borg \& Gall (1983:775) mengemukakan bahwa Research and Development prosedur penelitiannya mengikuti langkah-langkah seperti berikut ini : (1) survey pendahuluan; (2) pengembangan bahan ajar Bahasa Jerman berbasis pendekatan scaffolding yang akan dikembangkan; (3) mengadakan uji coba produk dan standarisai bahan ajar; (4) sosialisasi dan implementasi hasil penelitian. 
Buku ajar yang dikembangkan terdiri dari 5 lektion antara lain. Kennenlernen, Schule, Familie, Essen und Trinken dan Freizeit. Kelima tema ini dijabarkan dalam sub-sub tema dan disesuaikan dengan tingkat kemampuan siswa pada tingkat niveau A1. Buku ajar yang dikembangkan diujicobakan pada kelas X SMAN 7 Ambon dengan jumlah responden sebanyak 25 orang. Rata-rata presentase validasi mencapai nilai $80 \%$, sehingga bahan ajar yang dirancang unutk siswa SMA relatif baik. Dilihat dari tema yang dibahas cukup menarik dengan menggunakan metode Scaffolding karena smemiliki kelayakan yang tinggi dan layak digunakan.

\section{HASIL DAN PEMBAHASAN}

Hasil penelitian pengembangan bahan ajar dengan metode Scaffolding dapat dijadikan sebagai salah satu alternatif dalam pembelajaran dengan menggunakan tekni 4D. sebagai berikut:

(1) Tahap Pendefinisian. Pada tahap ini dilakukan analisis awal terhadap proses pembelajaran yang berlangsung selama ini serta analisis kebutuhan siswa. Berdasarkan analisis tersebut dirangcang buku ajar yang mampu menjawab permasalahan yang selama ini menjadai tantangan bagi pengembangan bahan ajar. Analisis mencakup kurikulum, silabus, RPP maupun bahan ajar yang selama ini dipakai . Analisis kurikulum dimaksudkan untuk menentukan materi-materi mana yang akan memerlukan bahan ajar dari sumber lainnya. Tahap ini dilakukan dengan cara melihat materi pokok dari materi yang akan diajarkan, kemudian kompetensi yang harus dikuasai oleh siswa. Metode yang dipakai untuk memudahkan siswa dalam pemahaman materi ajar adalah metode Scaffolding.

(2) Tahap Perancangan. Kegiatan yang dilakukan pada tahap perancangan ini adalah pemilihan media pembelajaran, pemilihan format pembelajaran, dan perancangan awal bahan ajar. Media pembelajaran yang diperlukan dalam pelaksanaan pembelajaran. Bahan ajar yang dilengkapi dengan gambar-gambar dan video yang disertai dengan alat bantu infokus dan alat pendengar (speaker) untuk mengaktifkan skemata mahasiswa terhadap materi yang akan disajikan. Pemilihan format untuk bahan ajar dibuat berwarna dengan tujuan agar mahasiswa tertarik dan termotivasi untuk belajar.

(3) Tahap Pengembangan. Kegiatan yang dilakukan pada tahap ini, yaitu penilaian ahli (validator). Validator) yang memvalidasi bahan ajar I terdiri dari dua orang yaitu, dosen pendidikan bahasa Jerman Universitas Pattimura. Berdasarkan penilaian validator maka hasil yang dicapai rata-rata adalah mencapai nilai $80 \%$, dapat disimpulkan bahwa bahan ajar yang disusun untuk kebutuhan bahasa Jerman pada kelas X dengan tingkat kemampuan setara A1. Bahan Ajar yang dikembangkan menggunakan model scaffolding. memiliki kelayakan yang tinggi dengan sedikit revisi. Langkah berikut, kemudian melakukan revisi terhadap bahan ajar dan silabus berdasarkan koreksi serta saran dari validator. Bahan ajar yang telah direvisi kemudian akan diujicobakan lagi. Hasil uji keterbacaan menunjukan, secara umum bahan ajar sudah pada tahap baik yaitu, antara 75 $\%$ - $100 \%$. Artinya, tingkat kelayakan bahan ajar yang dikembangkan sudah baik, namun perlu ditambahkan lebih banyak gambar-gambar yang sesuai dengan materi atau teks agar lebih menarik dan dapat membantu mengaktifkan skemata mahasiswa dalam memahami tema tersebut agar membuat pembelajaran jadi menarik.

(4) Tahap Desiminasi. Pada tahap keempat hasil pengembangan bahan ajar akan disebarkan luaskan bagi sekolah-sekolah lain dengan harapan kemampuan siswa memiliki kemampuan yang sama dalam memahami bahasa Jerman.

Selain hal tersebut di atas, pembelajar juga dapat membantu guru dalam memberikan umpan balik tentang kekuatan dan kelemahan kelas dengan menggunakan pendekatan scaffold. Disisi lain diskusi dengan peserta didik akan membantu guru apakah mereka berada di jalur yang benar atau apakah mereka harus melakukannya semacam modifikasi atau perubahan dalam praktik mengajar mereka. Peserta didik juga dapat membantu guru dalam memberikan umpan balik tentang kekuatan dan kelemahan kelas seperti berdiskusi dengan peserta didik akan membantu guru apakah mereka berada di jalur yang benar atau apakah mereka harus melakukannya semacam modifikasi atau perubahan dalam praktik mengajar mereka 
dan ini merupakan umpan balik yang baik bagi perbaikan proses belajar mengajar (Fania, Ghaemi, 2011: 1552-1553)

\section{KESIMPULAN}

Berdasarkan hasil penelitian pengembangan bahan ajar pada SMA berbasis Scaffolding dapat disimpulkan bahwa (1) Siswa lebih cenderung untuk belajar dengan menggunakan warna dan gambar yang menariki. (2). Teknik Scaffolding dalam penyusunan buku sangat memberi kontribusi dalam membentuk kognitif siswa dalam belajar. (3). Belajar bahasa asing terutama bahasa Jerman perlu dituntun dengan baik oleh karena itu buku ajar ini dirancang dengan panduan yang jelas sehingga dapat digunakan oleh setiap guru bahasa Jerman dengan baik.

Untuk meningkatkan hasil belajar guru dapat menggunakan buku ajar hasil penegmbangan ini dengan menggunakan panduan yang disusun dengan jelas dan rinci sehingga dapat digunakan oleh setiap guru bahasa Jerman. Disamping itu juga disarankan untuk dilakukan pengembangan bahan ajar bahasa Jerman dengan menggunakan teknik pengajaran lainnya dengan sampel atau responden yang berbeda.

\section{REFERENSI}

Beese, M., et al. 2014. DLL 16: Sprachbildung in allen Fachern. Klett-Langenscheidt. Muenchen.

Fani, T., dan Ghaemi, F. 2011. Implications of Vygotsky's Zone of Proximal Development (ZPD) in Teacher Education: ZPTD and Self-scaffolding. Procedia - Social and Behavioral Sciences. 29: 1549-1554. DOI: 10.1016/j.sbspro.2011.11.396.

Gibbons, P. 2015. Scaffolding language, scaffolding learning : teaching English language learners in the mainstream classroom. Second edition, Heinemann. Portsmouth, NH.

Könings, K.D., et al. 2018. Scaffolding peer-assessment skills: Risk of interference with learning domainspecific skills?. Learning and Instructions. 60: 85-94. DOI: 10.1016/j.learninstruc.2018.11.007

Many, J.E., Taylor, D. L., Wang, Y., Sachs, G.T., dan Schreiber, H. 2007. An Examination of Preservice Literacy Teacher' Initial Attemps to Provide Instructional Scaffolding. Reading Horizons: A Journal of Literacy and Language Arts. 48(1): 19-40.

Megawangi, R, Batifah, M, dan Dina, W.F. 2005. Pendidikan Holistik. Indonesia Heritage Foundation. Bogor

Nur, M, dan Wikandari, P. R. 2000. Pembelajaran Berpusat Pada Siswa dan Pendekatan Kontruktivitas dalam Pengajaran. UNESA. Surabaya

Popham, W. J., dan Baker, E. L. 2005. Teknik Mengajar Secara Sistematis. PT Rineka Cipta. Jakarta.

Rösler, dan Würffel. 2014. Lernmaterialien und Medien. Klett-Langenscheidt. München.

Rusman. 2010. Model-model Pembelajaran: Mengembangkan Profesionalisme Guru. PT Raja Grafindo Persada. Jakarta.

Rusman. 2012. Model-Model Pembelajaran. PT Raja Grafindo Persada. Jakarta.

Sharan, S. 2009. Handbook of Cooperative Learning. Imperium. Yogyakarta.

Suparno, A. S. 2000. Membangun Kompetensi Belajar. Direktorat Jenderal Pendidikan Tinggi, Departemen Pendidikan Nasional. Jakarta.

Syamsudin, A. R. 2006. Metodologi Penelitian Bahasa. PT Remaja Rosdakarya. Bandung

Thobroni, M, dan Mustofa, A. 2011. Belajar dan Pembelajaran. Ar-Ruzz Media. Yogyakarta

Trianto. 2007. Model Pembelajaran Inovatif Berorientasi Konstruktivistik. PT Prestasi Pustaka. Jakarta.

Trianto. 2010. Mengembangkan Model Pebelajaran Tematik. PT Prestasi Pustaka. Surabaya.

Yamin, M. H. 2011. Paradigma Baru Pembelajaran. Gaung Persada. Jakarta.

Yunus, A. 2012. Pembelajaran Berbasis Pendidikan Karakter. PT Refika Aditama. Bandung. 